\title{
One-Year Course of Olanzapine-Induced Diabetic Ketoacidosis: A Case Report
}

\author{
Mohammed Zain Ulabedin Adhoni ${ }^{a}$ Roomiyah Riyaz Assadi ${ }^{a}$ Saira Abbas ${ }^{b}$ \\ antern House Officer, Dubai Health Authority, Dubai, United Arab Emirates; 'b Internal Medicine, Rashid Hospital, \\ Dubai, United Arab Emirates
}

\section{Keywords}

Olanzapine · Diabetic ketoacidosis · Antipsychotics ·

Metabolic syndrome $\cdot$ Schizophrenia $\cdot$ Diabetes mellitus

\begin{abstract}
Second-generation antipsychotics, despite being highly effective, are among the drugs known to cause insulin resistance and metabolic syndrome, eventually leading to diabetes mellitus and less commonly diabetic ketoacidosis (DKA). Here, we present the case of a 21-year-old male, who was not previously known to have any comorbid factors but presented with DKA 1 year and 9 months after beginning treatment with olanzapine for an unspecified psychotic disorder requiring hospital admission and the resolution of the same following discontinuation of the drug. Our case report emphasizes the need for regular screening of patients requiring diabetogenic drugs, so that early identification of possible side effects can be noted and averted.
\end{abstract}

(c) 2021 The Author(s).

Published by S. Karger AG, Basel

\section{Introduction}

Second-generation antipsychotics (SGA) are the firstline medications used to treat psychotic disorders, primarily due to their high efficacy and a decreased risk for developing extrapyramidal side effects. However, among the more common side effects encountered with these drugs are their potential to cause excessive weight gain, insulin resistance, and subsequently diabetes mellitus and metabolic syndrome [1]

While the incidence of antipsychotic-induced diabetic ketoacidosis (DKA) is uncommon, the risk is noted to be the highest with medications such as olanzapine and clozapine $[2,3]$, risk factors of which include underlying type 1 diabetes, pre-diabetes, non-Caucasian ethnicity, acute physical illness, male gender, and middle age $[4,5]$. We would like to present a case of a young adult male, not previously known to have any medical conditions prior to treatment with olanzapine but who presented with olanzapine-induced DKA and was found to have type 2 diabetes mellitus (T2DM), obesity, and dyslipidemia along with persistently high blood pressures during admission, with resolution of the same following the discontinuation of olanzapine.

\section{Case Report}

A 21-year-old obese (BMI 39.6) African male presented to the Emergency Department with complaints of severe, central abdominal pain of 2-day duration along with a 1-day history of vomiting and loss of appetite. He denied any recent infections, fever, diarrhea, urinary complaints, or flu-like symptoms including cough. There was also no history of weight loss, excessive urination, increased thirst, or any other osmotic symptoms. His past medical history includes psychosis otherwise unspecified for which he was on olanzapine $10 \mathrm{mg}$ once daily for the last 1 year and 9 months karger@karger.com www.karger.com/dde

Karger $\stackrel{\text { '⿳亠丷厂 }}{=}$
(C) 2021 The Author(s)

Published by S. Karger AG, Basel

This is an Open Access article licensed under the Creative Commons Attribution-NonCommercial-4.0 International License (CC BY-NC) (http://www.karger.com/Services/OpenAccessLicense), applicable to the online version of the article only. Usage and distribution for commercial purposes requires written permission.
Correspondence to:

Mohammed Zain Ulabedin Adhoni, zainadhoni74@gmail.com 
Table 1. Initial lab values

\begin{tabular}{ll}
\hline Initial lab values & \\
\hline Random blood glucose, $\mathrm{mg} / \mathrm{dL}$ & 575 \\
POCT ketones & $>7$ \\
$\mathrm{HbA} 1 \mathrm{c}, \%$ & 12.5 \\
$\mathrm{Plasma}$ osmolarity, $\mathrm{mOsm} / \mathrm{kg} \cdot \mathrm{H}_{2} \mathrm{O}$ & 325 \\
$\mathrm{pH}$ & 7.24 \\
Sodium bicarbonate, $\mathrm{mmol} / \mathrm{dL}$ & 10.0 \\
WBC count & $10.5 \times 10^{3} / \mathrm{mL}$ \\
$\mathrm{CRP}, \mathrm{mg} / \mathrm{L}$ & 25.6 \\
Fasting cholesterol, $\mathrm{mg} / \mathrm{dL}$ & 234 \\
Triglycerides, $\mathrm{mg} / \mathrm{dL}$ & 183 \\
$\mathrm{LDL}$ cholesterol, $\mathrm{mg} / \mathrm{dL}$ & 150 \\
$\mathrm{HDL}$ cholesterol, $\mathrm{mg} / \mathrm{dL}$ & 47 \\
\hline
\end{tabular}

during which time he had gained around $30 \mathrm{~kg}$. He is one of the 3 children, all of whom are healthy with no underlying chronic illnesses; however, his mother is known to have diabetes mellitus type 2, and his maternal aunt is a known case of diabetes mellitus type 1 .

While in the emergency department, he was found to be tachycardic with a pulse of 121 beats per minute and elevated blood pressure going up to $147 / 81 \mathrm{~mm} \mathrm{Hg}$ but temperature, respiratory rate, and oxygen saturation were within normal limits $\left(36.9^{\circ} \mathrm{C}, 16\right.$ breaths per minute, and $98 \%$, respectively). His systemic examination findings were mostly unremarkable; his abdomen was soft and nontender but fatty with central adiposity, and he was noted to have acanthosis nigricans at the nape of his neck.

Antibodies for islet cell, insulin, and glutamic acid decarboxylase were also sent. His initial lab investigations showed mild acidosis and elevated POCT ketones with significantly elevated blood glucose and serum osmolality (Tables 1 and 2).

He was admitted and started on treatment according to our local DKA protocol guidelines. His olanzapine was discontinued at admission. He improved clinically and symptomatically and was out of DKA within $48 \mathrm{~h}$. After resolution of DKA, he was switched to aripiprazole $10 \mathrm{mg}$ once a day by the Psychiatry team. He was discharged on 26 units of insulin glargine and 8 units of insulin lispro before meals with correction doses. He was also advised lifestyle changes, including a healthier diet and exercise. Later, his islet cell, insulin, and glutamic acid decarboxylase antibody tests were reported as negative, and the patient was diagnosed to have T2DM.

During follow-up, 1 month after discharge, the mother reported occasional episodes of hypoglycemia, following which his premeal insulin was discontinued. His dose of basal insulin glargine was also decreased to 10 units, and he was started on $750 \mathrm{mg}$ of metformin once daily which was later increased to twice daily after concerns regarding tolerance for the medication were cleared. $\mathrm{He}$ was eventually weaned off insulin.

Presently, it has been 1 year after discharge, and the patient is completely off all oral antidiabetic agents, and he continues to maintain a healthier lifestyle. He has lost weight, and the current BMI is 25.38 .

One-Year Course of Olanzapine-Induced

Diabetic Ketoacidosis: A Case Report
Table 2. Follow-up lab values

\begin{tabular}{|c|c|c|}
\hline Follow-up lab tests & Result & $\begin{array}{l}\text { Timing of test after } \\
\text { admission }\end{array}$ \\
\hline \multicolumn{3}{|l|}{ Islet cell, insulin, and } \\
\hline glutamate antibodies & Negative & During admission \\
\hline $\mathrm{HbA} 1 \mathrm{c}$ & $5.7 \%$ & 3 months \\
\hline C-peptide & $0.68 \mathrm{nmol} / \mathrm{L}$ & 3 months \\
\hline $\mathrm{HbA1c}$ & $5.2 \%$ & 6 months \\
\hline Total cholesterol & $161 \mathrm{mg} / \mathrm{dL}$ & 6 months \\
\hline Triglycerides & $60 \mathrm{mg} / \mathrm{dL}$ & 6 months \\
\hline LDL cholesterol & $99 \mathrm{mg} / \mathrm{dL}$ & 6 months \\
\hline HDL cholesterol & $50 \mathrm{mg} / \mathrm{dL}$ & 6 months \\
\hline
\end{tabular}

\section{Discussion}

While antipsychotics are regarded as the major culprit in the development of glucose dysregulation among those with schizophrenia, studies indicate that schizophrenics are more likely to develop diabetes mellitus than the general population by $2-4$ times. This is further underscored by a study that indicated that there was a higher prevalence of diabetes among patients with schizophrenia even before atypical antipsychotics were in widespread use [6].

Among antipsychotics, it is the SGA that are associated with the development of diabetes, with olanzapine and clozapine having the highest risk [1,2]. Ziprasidone and aripiprazole have risk similar to nonusers of antipsychotics or users of first-generation antipsychotics $[7,8]$. This association may range from mild hyperglycemia to severe medical emergencies, including the hyperosmolar hyperglycemic state or even DKA, usually within 6 months of initiation of treatment with the offending drug. In a study of 83 patients with antipsychotic-induced DKA, DKA was the first clinical presentation in the majority of patients with newly diagnosed diabetes. Prodromal symptoms (such as polydipsia, polyuria, and weakness) were reported only in 30 patients and lasted from 1 day to 4 weeks [5].

Preferred treatment after development of antipsychotic-induced DKA in T2DM patients include (1) cessation of the suspected antipsychotic drug and substitution to another less diabetogenic antipsychotic, (2) standard treatment of DKA, (3) tapering of insulin as per glycemic values with reduction of prandial followed by basal insulin, and (4) metformin to be introduced in order to reduce insulin resistance barring any contraindications. The maximal dose of $2 \mathrm{~g}$ per day to be taken twice daily in di-

Dubai Diabetes Endocrinol J 2021;27:158-16 
vided doses should be started until the glycated hemoglobin (HbA1c) reaches $<6 \%$. At that point, it is recommended to reduce the daily dose of metformin by half and monitor $\mathrm{HbAlc}$ for the next 3-6 months. If $\mathrm{HbAlc}$ is $<6 \%$, metformin can be discontinued [9].

The possibility of DKA may be significantly reduced with careful monitoring of patients on SGA, especially olanzapine, for metabolic complications. Baseline investigations according to the American Diabetes Association (ADA) include a personal and family history of obesity, diabetes, dyslipidemia, hypertension, and cardiovascular disease along with measurement of BMI, waist circumference, blood pressure, fasting plasma glucose and lipid profile, and weight to be ideally reassessed at 4,8 , and 12 weeks and quarterly thereafter after initiating or changing SGA therapy. Fasting plasma glucose, lipid levels, and blood pressure should also be reassessed 3 months after initiation of antipsychotics with at least annual measurement of blood pressure and plasma glucose [10].

The patient in this case had a number of risk factors that further precipitated the development of T2DM eventually leading to this episode, such as being a male of African origin and a positive family history of diabetes. Although the patient's initial presentation fits the diagnostic criteria of DKA, there appears to be some degree of overlap with hyperosmolar hyperglycemic state (HHS) as the patient had elevated plasma osmolality at $325 \mathrm{mOsm} /$ $\mathrm{kg} . \mathrm{H}_{2} \mathrm{O}$ with a very high blood glucose level of $575 \mathrm{mg} / \mathrm{dL}$ and only mild acidosis. Overlap between DKA and hyperglycemic hyperosmolar state has been reported in around a third of cases, and our patient probably falls in this category [11].

No other precipitating factor was identified, and there was no evidence of any recent or ongoing infection or stressor at the time of presentation. With the adoption of a healthy lifestyle and discontinuation of olanzapine, the patient currently has a BMI of 25.4 and no longer requires medications to control his blood sugar.

\section{Conclusion}

The findings of our case suggest that DKA may be the primary presentation of type 2 diabetes in individuals requiring atypical antipsychotics even in the absence of prodromal symptoms and must be used with caution in those suspected to have other risk factors of insulin resistance. This possibility may be averted by ensuring awareness of this possibility among treating psychiatrists and the patients' families along with regular screening as per

the ADA guidelines. Those with a history of antipsychotic-induced DKA should continue to have regular screening for metabolic complications, so that they can be identified and managed early.

\section{Statement of Ethics}

The case report complies with the guidelines for human studies in accordance with the World Medical Association Declaration of Helsinki. Written informed consent for publishing the case was taken from the father as the patient is suffering from a psychotic spectrum disorder. Ethical approval is not required according to the Dubai Health Authority Ethics Committee policies.

\section{Conflict of Interest Statement}

The authors declared no potential conflicts of interest with respect to the research, authorship, and/or publication of this article.

\section{Funding Sources}

The authors have not declared a specific grant for this research from any funding agency in the public, commercial, or not-forprofit sectors.

\section{Author Contributions}

All authors were involved in the acquisition and interpretation of the data, the article's conception and design, and the final approval of the version to be published.

\section{Data Availability Statement}

All data generated or analyzed during this study are included in this article. Further enquiries can be directed to the corresponding author.

References

Dubai Diabetes Endocrinol J 2021;27:158-161 DOI: $10.1159 / 000519726$
1 Wilson DR, D'Souza L, Sarkar N, Newton M, Hammond C. New-onset diabetes and ketoacidosis with atypical antipsychotics. Schizophr Res. 2003;59(1):1-6.

2 Koller EA, Doraiswamy PM. Olanzapine-associated diabetes mellitus. Pharmacotherapy. 2002;22(7):841-52.

3 Koller E, Schneider B, Bennett K, Dubitsky G Clozapine-associated diabetes. Am J Med. 2001;111(9):716-23.

4 English P, Williams G. Hyperglycaemic crises and lactic acidosis in diabetes mellitus. Postgrad Med J. 2004;80(943):253-61. 
5 Vuk A, Kuzman MR, Baretic M, Osvatic MM. Diabetic ketoacidosis associated with antipsychotic drugs: case reports and a review of literature. Psychiatr Danub. 2017;29(2):121-35.

6 Dixon L, Weiden P, Delahanty J, Goldberg R, Postrado L, Lucksted A, et al. Prevalence and correlates of diabetes in national schizophrenia samples. Schizophr Bull. 2000;26(4):90312.

7 Jin H, Meyer JM, Jeste DV. Phenomenology of and risk factors for new-onset diabetes mellitus and diabetic ketoacidosis associated with atypical antipsychotics: an analysis of 45 published cases. Ann Clin Psychiatry. 2002;14(1): 59-64.
8 Lindenmayer JP, Czobor P, Volavka J, Citrome L, Sheitman B, mcevoy JP, et al. Changes in glucose and cholesterol levels in patients with schizophrenia treated with typical or atypical antipsychotics. Am J Psychiatry. 2003;160(2):290-6.

9 Vuk A, Baretic M, Osvatic MM, Filipcic I, Jovanovic N, Kuzman MR. Treatment of diabetic ketoacidosis associated with antipsychotic medication: literature review. J Clin Psychopharmacol. 2017;37(5):584-9.
10 American Diabetes Association; American Psychiatric Association; American Association of Clinical Endocrinologists; North American Association for the Study of Obesity. Consensus development conference on antipsychotic drugs and obesity and diabetes. Diabetes Care. 2004 Feb;27(2):596-601.

11 Kitabchi AE, Umpierrez GE, Murphy MB, Kreisberg RA. Hyperglycemic crises in adult patients with diabetes: a consensus statement from the American Diabetes Association. Diabetes Care. 2006 Dec;29(12):2739-48. 